\title{
UMA ANÁLISE DA ESCRITA NOS TEXTOS DE ALUNOS DO ENSINO FUNDAMENTAL
}

\author{
Paulo Pereira dos Santos* \\ Eliane Pereira Machado Soares**
}

RESUMO: Este trabalho apresenta uma pesquisa sobre os erros ortográficos decorrentes da influência da fala na escrita e os decorrentes da falta de familiaridade do aluno com as convenções ortográficas, nas produções textuais escritas de alunos do $6^{\circ}$ e $9^{\circ}$ anos do ensino fundamental II, de uma escola pública, no município de Parauapebas (PA). Para tanto, tem-se como fundamento teórico as abordagens de Morais (2003), Nóbrega (2013), Bortoni-Ricardo (2005); Mollica (2016); entre outros. Por se tratar de uma pesquisa de natureza quali-quantitativa, os dados linguísticos foram colhidos a partir de uma atividade de produção de textos (artigo de opinião e relato pessoal), resultando em um corpus com 1.638 dados. Os resultados obtidos após o tratamento de dados por meio do programa computacional Goldvarb X, permitiram concluir que os alunos chegam ao $6^{\circ}$ ano do ensino fundamental apresentando mais problemas ortográficos referentes à interferência da fala na escrita (72,7\%), do que aqueles decorrentes de problemas de convenção ortográfica (27,3\%). Além disso, concluímos que esses problemas ortográficos estão correlacionados tanto a fatores extralinguísticos (sexo, renda, escolaridade da mãe, ano escolar), quanto a fatores linguísticos (gênero textual, classe gramatical).

PALAVRAS-CHAVE: Convenção ortográfica; Erros ortográficos; Interferência da fala na escrita.

\section{Introdução}

Este artigo é um recorte da pesquisa de mestrado em andamento intitulada "Marcas de oralidade nos textos escritos de alunos do Ensino Fundamental: uma proposta de intervenção por meio digital", com o objetivo geral de identificar e analisar os erros ortográficos presentes nos textos escritos e as motivações para a sua ocorrência nas produções dos alunos dos $6^{\circ}$ e $9^{\circ}$ anos numa escola pública, no município de Parauapebas, no sudeste do Pará.

Sabe-se que nas produções escritas dos alunos, principalmente, daqueles que estão no processo de aquisição da escrita, há a ocorrência de muitos erros ortográficos e esses precisam ser analisados e corrigidos para que não se perpetuem nos anos posteriores. As

\footnotetext{
* Mestrando em Letras pela Universidade Federal do Sul e Sudeste do Pará (Unifesspa).

${ }^{* *}$ Doutora em Linguística pela Universidade Federal do Ceará (UFC). Professora Associada I da Universidade Federal do Sul e Sudeste Pará (Unifesspa).
} 
principais causas podem ser atribuídas, por hipótese, à complexidade do sistema ortográfico e às influências da fala, por razões sociolinguísticas.

Muitos teóricos discutem o tema sob tais primas, tais como Morais (2003), Nóbrega (2013); Travaglia (2009), dentre outros, abordando também a importância de um ensino da língua materna que faça uma intervenção adequada a questões de escrita.

Com base nesses autores, realizamos nossa pesquisa e discutimos o tema aqui abordado. A partir dos dados obtidos, proporemos um projeto de intervenção pedagógica, o qual não se constitui objeto de discussão deste artigo, por ainda estar em construção e por questões de espaço.

\section{A linguagem oral e escrita}

A linguagem é fundamental ao ser humano. É por meio da linguagem que ele consegue interagir socialmente, organizar e transmitir conhecimentos, expressar sentimentos, manifestar pensamentos e opiniões.

Para tanto, o indivíduo utiliza diversos tipos de linguagens, dentre elas a modalidade oral e a modalidade escrita. A primeira, manifestada por meio da fala, acompanhada de posturas corporais, gesticulações, expressões faciais, sotaques etc. A segunda, representada inicialmente por pictogramas, em seguida por ideogramas e por fim, sinais gráficos, sendo considerada imprescindível no mundo atual.

Devido seu aprendizado não espontâneo, sua importância no mundo como registro, ser objeto de ensino específico, ser um sistema de notação cheio de regras que vão além da relação som e letra, a escrita, geralmente, é avaliada "como de estrutura complexa, formal e abstrata, enquanto a fala, de estrutura simples ou desestruturada, informal, concreta e dependente do contexto" (FÁVERO, 2002 p. 08).

Nessa perspectiva, equivocada, a escrita acaba recebendo um maior prestígio na sociedade atual, sendo considerada, no senso comum e até no âmbito pedagógico, como uma modalidade superior à fala. Fato é que não podemos dizer que a língua falada e a língua escrita são semelhantes ou simplesmente afirmar que a escrita é a representação da fala, pois são duas maneiras diferentes de manifestações linguísticas. Mas, apesar de serem 
dois sistemas distintos, são complementares e estão presentes em todos os processos sociocomunicativos.

As crianças aprendem a língua oral naturalmente e de maneira espontânea em sua convivência familiar e ao iniciarem a sua trajetória escolar já possuem domínio da gramática da língua, em especial da língua falada ao seu redor, ou seja, a língua do seu grupo social. Isso ocorre porque as crianças começam a ter contato com a língua oral desde o seu nascimento. Segundo Cagliari (2002, p. 16), esse processo de aquisição da linguagem se desenvolve na criança "a partir, aproximadamente do seu primeiro ano de idade" e vai se ampliando conforme o decorrer dos anos.

Já a aprendizagem da linguagem escrita não é espontânea nem natural, por isso necessita ser ensinada, o que é papel, principalmente, da escola, pois ela possui competência para desenvolver tal habilidade, e deve se concentrar nesse aprendizado nos anos iniciais, como afirma a Base Nacional Comum Curricular (BNCC, 2017). No espaço escolar, a criança é introduzida como aprendiz na cultura letrada e se depara com um sistema alfabético de escrita muito complexo. Mesmo que a criança tenha conhecimentos e habilidades da língua falada, a modalidade baseada no uso de grafemas é totalmente nova para ela. Neste ambiente de aprendizagem, a maior parte das atividades realizadas é basicamente centrado na escrita.

A teoria psicogenética da escrita explica que a criança adquire a escrita por meio de um processo gradual e dividido em fases, "pré-silábico, silábico, silábico-alfabético e alfabético" (FERREIRO; TEBEROSKY, 1999). Após esse aprendizado, a criança se depara com outro desafio linguístico, o domínio ortográfico da língua escrita padrão. Entretanto, esse nem sempre ocorre de maneira completa e isso pode ser identificado nos seus escritos.

\section{A variação linguística no contexto escolar e a influência da fala na escrita}

Há muito tempo a gramática normativa se impõe sobre o ensino da língua materna. Entretanto, nas últimas décadas, os estudos das variedades linguísticas refletiram nas diretrizes oficiais para o ensino de língua materna e, com isso, os professores começaram a se adequar a um ensino mais pautado na valorização e no respeito dos diferentes modos de 
falar. Mesmo assim, por nossa experiência, podemos afirmar que muitos docentes se sentem inseguros e não sabem como agir diante dos popularmente chamados "erros de português", cometidos pelos alunos na escrita, especialmente os influenciados pela fala.

Diante disso, cabe à instituição escolar proporcionar situações que viabilizem os diferentes usos da língua de acordo com o cotidiano vivido pelos alunos. Nesse sentido, Bortoni-Ricardo (2005, p. 15) afirma que "A escola não pode ignorar as diferenças sociolinguísticas. Os professores e seus alunos precisam estar conscientes de que existem diferentes formas de se dizer a mesma coisa".

Quando o aluno entra na escola, naturalmente já possui um domínio significativo da sua língua, especialmente a falada. Pois no convívio familiar encontra-se um ambiente no qual essa linguagem é predominante. Na escola, ele precisa aprender a reconhecer que há uma gama de variedades linguísticas e que cada uma está relacionada a uma situação comunicativa diferente. Nesta conjuntura, o objetivo do ensino da língua materna é o de proporcionar situações de usos linguísticos que permitirão ao aluno desenvolver a sua competência comunicativa, isto é, "a capacidade do usuário de empregar adequadamente a língua nas diversas situações de comunicação" (TRAVAGLIA, 2009, p. 17).

Os diversos falares que formam a língua portuguesa decorrem de variados fatores como grupos etários, gênero, nível socioeconômico, grau de instrução, região e redes sociais. Segundo Bortoni-Ricardo (2004, p. 49), "Todos esses fatores representam os atributos de um falante: sua idade, sexo, seu status econômico e nível de escolarização" que é própria da individualidade da pessoa. Por isso, é necessário que essas formas variadas de falar sejam respeitadas para que não se tornem uma fonte de preconceito linguístico.

Mesmo diante de estudos sociolinguísticos que buscam uma valorização dos usos variados da língua, o que se percebe, ainda, é uma polarização entre língua padrão e não padrão, com preferência, por uma determinada forma da língua, e quase sempre, a norma culta, como afirma Travaglia, (2009, p. 41) "Se acredita que em diferentes tipos de situação tem-se ou deve-se usar a língua de modos variados, não há por que, ao realizar as atividades de ensino/aprendizagem da língua materna, insistir no trabalho apenas com uma das variedades, a norma culta." 
Inúmeros estudos na área da sociolinguística nos levam a compreender acerca dos diversos mecanismos que controlam "os usos das variedades coloquiais e das variedades padrão do atual português brasileiro falado" (MOLLICA, 2016, p. 16). Por meio desses trabalhos sociolinguísticos, compreendemos a sistematicidade e dinamicidade das línguas e nos leva a um melhor entendimento sobre as crenças referentes aos usos linguísticos, evitando, assim, atitudes preconceituosas em relação às variações linguísticas, principalmente as estigmatizadas.

A influência da fala sobre a escrita é significativa e bastante perceptível na escrita dos falantes. Dependendo da comunidade de fala, os indivíduos apresentam uma maior frequência de traços. Isso é notável quando comparamos a fala urbana com a fala de comunidades rurais (MOLLICA, 2016, p. 19). As variantes dessa última são motivos de atitudes preconceituosas fora do ambiente rural por se distanciarem da variedade de prestígio, urbana.

Contudo, podemos encontrar marcas da oralidade em textos escritos, evidenciando a influência do oral no escrito, especialmente, em alunos em processo de escolarização. Durante o processo de alfabetização, a língua falada é a principal referência que as crianças adotam para praticar a atividade de escrita, resultando assim, em diversos erros ortográficos. Sobre isso, Nóbrega (2013, p. 44) afirma que devido às relações biunívocas entre grafemas e fonemas serem pouco numerosas e o fato de um mesmo fonema ser representado por vários grafemas e um mesmo grafema ser representado por diferentes fonemas, transcrever a escrita resulta em numerosos problemas ortográficos.

Nesse contexto, é necessário um ensino reflexivo sobre a ortografia que é um ponto de partida para as reflexões sobre os usos variados da língua, pois, "ao tratar o desvio da norma ortográfica como um lugar privilegiado para descrever os fatos da língua, chama-se atenção para as diferenças entre modalidade falada e escrita e analisam-se os diferentes componentes do sistema linguístico: fonética, morfologia, sintaxe e semântica" (NÓBREGA, 2013, p. 45). 


\section{O ensino da ortografia}

A ortografia não é simplesmente um conjunto de normas, cujo domínio nos permite escrever bem, mas, "trata-se de um complexo sistema que estabelece os valores que os grafemas podem assumir em função de uma palavra; prefixos e sufixos; desinências; radicais; e recursos que nos ajudam a distinguir palavras que soam semelhantes" (NÓBREGA, 2013, p. 12). Para essa autora, a ortografia é um recurso capaz de "cristalizar" na escrita as diferentes maneiras de falar dos usuários de uma mesma língua, pois, escrevendo de forma unificada, podemos nos comunicar mais facilmente.

Assim, ao considerar a ortografia como um sistema resulta em implicações para seu ensino. Por ser vista como um conjunto de normas, a prática desse sistema permite criar uma tipologia de erros, uma tipologia de atividades, indicadores de avaliação mais específicos, além de princípios orientadores para a formulação de expectativas de aprendizagem. A autora complementa que, por outro lado, aprender as regularidades do sistema ortográfico, ajuda o aluno aliviar a sobrecarga de decidir como cada palavra deve ser escrita. Livre dessa carga, o estudante poderá dedica-se a ampliar seu domínio da linguagem escrita.

Estudos comprovam que as maiores dificuldades dos alunos, no que concerne ao aprendizado das normas ortográficas estão relacionadas às regularidades e irregularidades da ortografia. Muitas palavras não possuem regras, enquanto outras são determinadas por elas. A primeira leva as crianças e, até mesmo, os adultos a cometerem erros na hora de escrever.

No caso das dificuldades irregulares, as palavras são justificadas pela tradição de uso ou pela origem etimológica, por exemplo: o uso do H na palavra "homem". Neste caso, o aluno tem que memorizar a forma correta de escrever o termo. Já as dificuldades regulares são estabelecidas por regras que se aplicam para várias, ou todas as palavras referentes à uma determinada dificuldade, por exemplo: uso do S e SS nas palavras "cansar" e "cassar" (MORAIS, 2003, p. 27-28). As regularidades ortográficas permitem que a criança tenha uma ideia antecipada do termo que será escrito, evitando erros na grafia, tendo em vista as regras que as determinam. 
Devido aos seus primeiros anos de contato com a escrita, muitos erros ortográficos cometidos pelos alunos são, portanto, compreensíveis. Esses problemas ortográficos, revelam a necessidade de um mediador para que os ajudem a dominar as "facetas da escrita" (Morais 2003, p. 22). Ao serem analisados de forma sistemática, esses erros podem revelar ao professor qual o nível de conhecimento do aluno e quais as possíveis dificuldades que os alunos estão apresentando no processo de aquisição da escrita.

\section{Os erros ortográficos em nossa pesquisa: resultados e discussão}

Para a constituição do corpus de nossa pesquisa foram utilizadas duas produções de textos dos alunos, um artigo de opinião e um relato pessoal, de duas turmas, formada por 58 alunos, na faixa etária de 11-15 (onze-quinze) anos, uma de $6^{\circ}$ ano e outra de $9^{\circ}$ ano de uma escola pública, no município de Parauapebas-PA, a fim de se verificar se os problemas de escrita permaneciam ou diminuíam conforme o avanço do nível escolar.

Para a análise dos dados foi utilizado o programa computacional Goldvarb X, que é uma ferramenta relevante nos estudos da Sociolinguística Variacionista, que tem a capacidade de processar um grande volume de dados linguísticos, com objetivo de definir uma regra variável que ajude a explicar um determinado fenômeno sociolinguístico, revelando ao pesquisador quais as variáveis mais relevantes na produção do fenômeno estudado (LORANDI, 2013).

Como variável dependente (linguísticas), tomamos os problemas de escrita, com duas variáveis: os erros ortográficos decorrentes da interferência da fala e os erros ortográficos decorrentes de problemas de convenção ortográfica. Em relação aos erros ortográficos que sofrem influência pela língua falada, escolhemos os seguintes fenômenos fonológicos para serem analisados: alteamento vocálico, apagamento, ditongação, monotongação, hipersegmentação e hipossegmentação. A escolha desses eventos linguísticos se deu pelo fato de acreditar, hipoteticamente, que esses fenômenos são os mais ocorrentes nas produções escritas.

Como variáveis independentes extralinguísticas, foram escolhidas sexo/gênero (masculino ou feminino), renda familiar (baixa e média), escolaridade da mãe (superior, 
médio ou fundamental) e a série do aluno $\left(6^{\circ}\right.$ ou $9^{\circ}$ ano). Em relação às variáveis independentes linguísticas, escolhemos os gêneros textuais artigo de opinião e relato pessoal. Ainda no campo linguístico, escolhemos as seguintes classes gramaticais substantivo; adjetivo, advérbio, conjunção, pronome e verbo.

\section{Análise dos resultados}

A constituição da amostra se deu com 116 produções textuais escritas, das quais 29 são textos de alunos do $6^{\circ}$ ano e 29 textos de alunos do $9^{\circ}$ ano. Os dados a seguir, que serão ilustrados por meio de gráficos, foram obtidos em rodadas binárias e eneárias nas quais foram cruzados os problemas de ortografia influenciados pela fala e os problemas por desconhecimento da convenção ortográfica com as variáveis extralinguísticas e linguísticas, por meio do programa Goldvarb X. Na legenda dos gráficos, a variante "erros ortográficos por interferência da fala", será ilustrada apenas como "interferência da fala" e os "erros ortográficos por problemas de convenção ortográfica", será ilustrado como "convenção ortográfica". Por uma questão de simplificação, para melhor visualização e compreensão dos resultados, optamos por apresentar neste trabalho os dados em percentuais em forma de gráfico.

Os erros ortográficos encontrados nas produções escritas dos alunos totalizaram 1.638 ocorrências. Nos textos do $6^{\circ}$ ano, foram encontradas 1.091 ocorrências e do $9^{\circ}$ ano foram encontradas 547 ocorrências. Considerando a totalidade de erros encontrados na pesquisa, obtivemos os percentuais representados no gráfico a seguir:

Gráfico 1 - Frequência dos erros ortográficos.

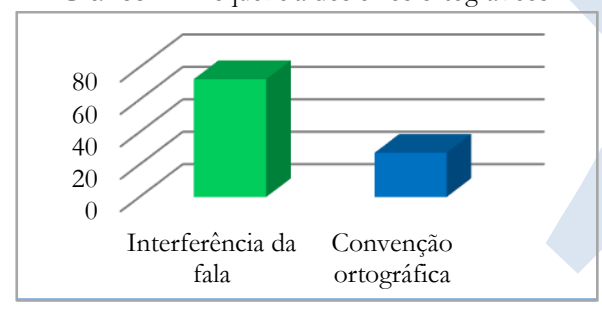

Fonte: Elaboração dos autores. 
A observação dos percentuais, ilustrados no gráfico 1, nos mostra uma diferença significativa considerando essas duas variantes estudadas. Os problemas de ortografia decorrentes da influência da fala correspondem a $72,7 \%$ dos erros ortográficos equivalentes a 1.191 ocorrências, sobrepondo-se aos erros decorrentes do desconhecimento de convenção ortográfica, correspondendo a 27,3\%, equivalente a 447 ocorrências. O que demonstra a força do oral, da variação linguística sobre a escrita.

Ainda de maneira geral, levando em consideração os processos fonológicos escolhidos, os erros foram distribuídos, conforme o gráfico 2:

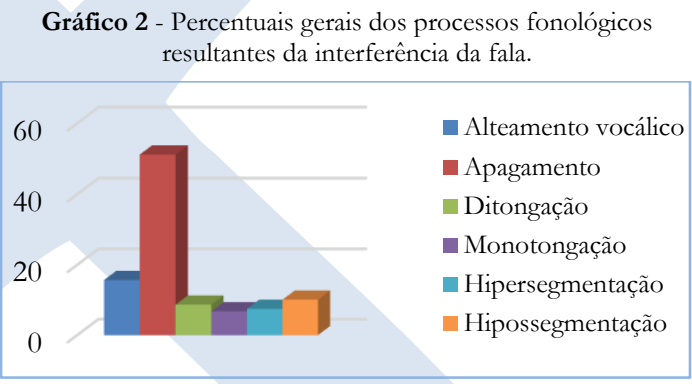

Fonte: Elaboração dos autores.

O processo fonológico mais expressivo foi o apagamento, com 453 ocorrências, representando $51,2 \%$ do total, seguido de alteamento vocálico, com 139, correspondendo a 15,7\%; logo depois, hipossegmentação, com 89 ocorrências, correspondendo a 10,1\%; ditongação, com 77 ocorrências, correspondendo a 8,7\%; e com menos expressividade, o processo de monotongação, com 60 ocorrências, representando 6,8\%.

Gráfico 3 - Processos fonológicos resultantes da interferência da fala na escrita do $6^{\circ}$ ano.

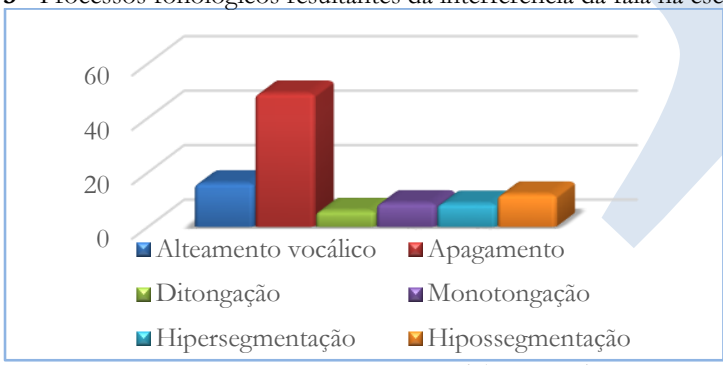

Fonte: Elaboração dos autores. 
Gráfico 4 - Processos fonológicos resultantes da interferência da fala na escrita do $9^{\circ}$ ano.

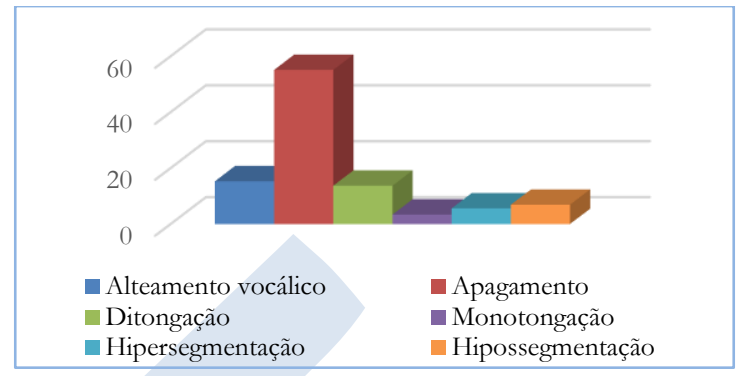

Fonte: Elaboração dos autores.

No gráfico 3, percebemos que o maior percentual está relacionado ao apagamento $(49 \%)$ e a menor à ditongação (5,9\%). No gráfico 4 , o resultado é um pouco semelhante em termo de ocorrência. Assim como a série anterior, o apagamento $(55,1 \%)$ apresenta o maior percentual com 177 ocorrências; e o menor a monotongação (3,4\%). É interessante notar que os resultados estão muito próximos e indicam até que o apagamento é persistente, sendo ainda maior no $9^{\circ}$ ano, contrariando a ideia de que maior escolarização poderia fazer com que este fenômeno ocorresse menos ou até fosse superado. De igual modo, a ditongação também aumentou. Por outro lado, o alteamento vocálico, a monotongação, a hipersegmentação e a hipossegmentação diminuíram.

Gráfico 5 - Erros ortográficos considerando o ano escolar.

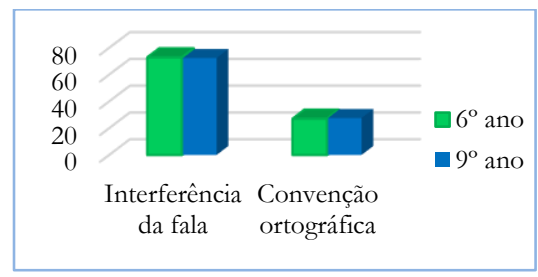

Fonte: Elaboração dos autores.
Gráfico 6 - Comparativo: número de ocorrências de erros ortográficos.

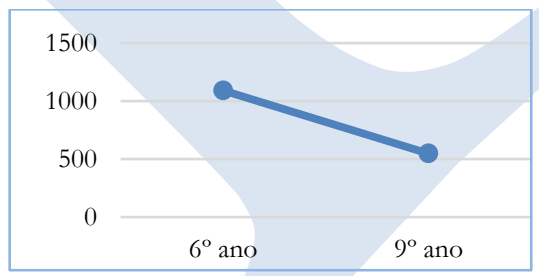

Fonte: Elaboração dos autores.

Como podemos observar no gráfico 5, os percentuais de ocorrências por influência da fala são bastante expressivos nas duas etapas. Sendo 72,9\% de ocorrências nas produções dos alunos do $6^{\circ}$ ano, e $72,4 \%$ de ocorrências nos textos dos alunos do $9^{\circ}$ ano. Já a ocorrência de erros ortográficos por problemas de convenção ortográfica representa 27,1\% 
no $6^{\circ}$ ano e $27,6 \%$ no $9^{\circ}$ ano. Esses resultados mostram que os alunos ao chegarem no $6^{\circ}$ ano apresentam muitas dificuldades de escrita em seu processo de alfabetização.

Percebemos no gráfico 6, que essas dificuldades ortográficas tendem a diminuir nos anos posteriores, porém essa redução ocorre apenas pela metade, continuando, ainda, de forma expressiva, tendo em vista que o $9^{\circ}$ ano é a série final do ensino fundamental e espera-se que os alunos dominem as regras ortográficas produzindo textos coesos e coerentes sem problemas de escrita.

O gráfico 7 mostra o índice das ocorrências em função do sexo/gênero.

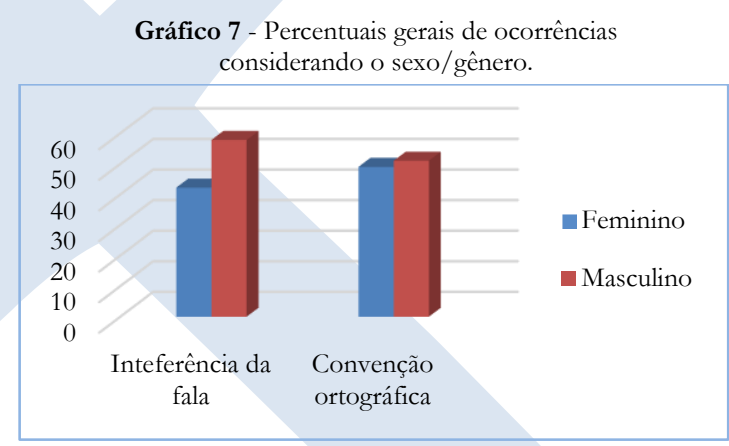

Fonte: Elaboração dos autores.

Constatamos que o sexo masculino (57,8\%), apresentou um percentual maior de erros ortográficos referentes à interferência da fala, já o sexo feminino $(42,2 \%)$ apresentou um menor percentual. Em relação aos outros erros ortográficos decorrentes dos problemas de convenção da escrita, o sexo masculino (51\%), também, apresentou um percentual maior comparado ao sexo feminino $(49 \%)$. Vale ressaltar que a diferença de ocorrências entre o sexo feminino e o masculino na segunda variante é mínima, equivalente a $2 \%$. Esses dados apontam que os meninos apresentam mais problemas de escrita do que as meninas, confirmando as diversas pesquisas que investigam a correlação entre variação linguística e o fator sexo/gênero, nas quais demonstram que esse fator é significativo na mudança linguística e afirmam que o sexo feminino possui "uma maior sensibilidade ao prestígio social atribuído pela comunidade às variantes linguísticas" (PAIVA, 2010, p. 37). 
Isolando-se os fatores feminino e masculino, obtemos a seguinte distribuição:

Gráfico 8 - Percentuais de erros ortográficos considerando o fator feminino.

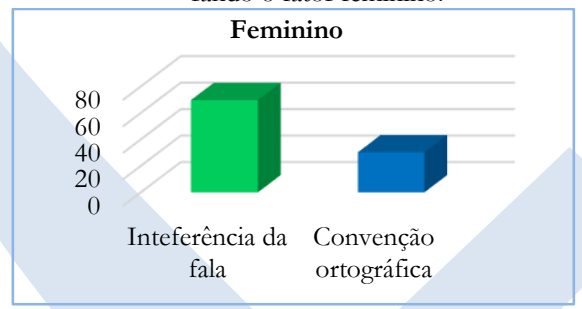

Fonte: Elaboração dos autores.
Gráfico 9 - Percentuais de erros ortográficos considerando o fator masculino.

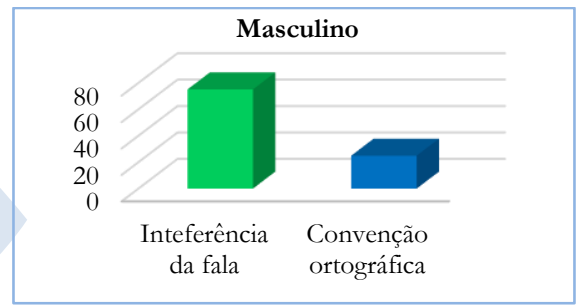

Fonte: Elaboração dos autores.

Observando os gráficos 8 e 9, constatamos que, tanto os meninos $(75,1 \%)$ quanto as meninas $(69,7 \%)$ apresentaram um maior percentual de erros ortográficos decorrentes da interferência da fala. Para ambos os sexos, prevalece o erro decorrentes das influências pela da oralidade; entretanto, com maiores índices para o sexo masculino. Ao contrário, os outros erros ortográficos apresentaram percentuais mais baixos, o que demonstra que a fala exerce forte influência nas duas categorias, porém as meninas sentem mais a pressão social e apresentam menos erros, por outro lado, de forma inesperada, apresentam mais erros decorrentes da convenção ortográfica (30,3\%), o que demonstra maior dificuldade de aprendizado do código escrito.

Levando em consideração o fator sexo/gênero e ano escolar sobre as variantes estudadas, temos os seguintes índices.

Gráfico 10 - Percentuais de erros ortográficos considerando o fator sexo e ano escolar no $6^{\circ}$ ano do ensino fundamental.

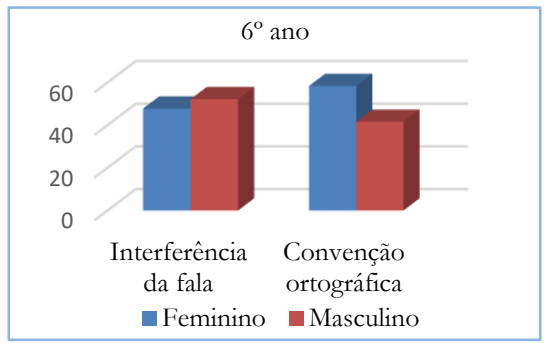

Fonte: Elaboração dos autores.
Gráfico 11 - Percentuais de erros ortográficos considerando o fator sexo e ano escolar no $9^{\circ}$ do ensino fundamental.

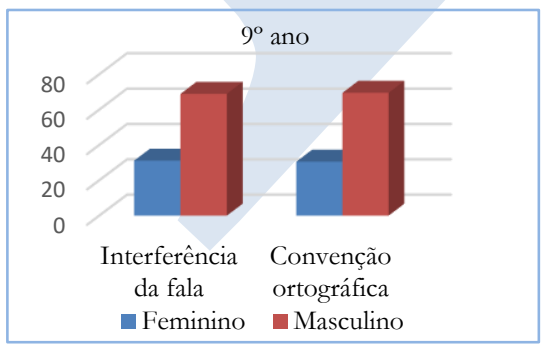

Fonte: Elaboração dos autores. 
O gráfico 10 mostra a distribuição de ocorrências no $6^{\circ}$ ano, das quais o sexo masculino $(52,2 \%)$ apresentou um percentual maior de erros ortográficos referentes à interferência da fala, já o sexo feminino $(47,8 \%)$ apresentou um menor percentual. Em relação aos outros erros ortográficos devido aos problemas de convenção, o sexo feminino apresentou um percentual maior $(58,4 \%)$ comparado ao sexo masculino (41,6\%). Entretanto, esses dados mostram uma evolução na escrita feminina no que tange aos erros decorrentes da convenção, pois diminuem com o aumento da escolaridade, como se vê no gráfico 11.

Outro fator analisado foi a ocorrência de erros ortográficos motivados pela renda familiar. Para fazer a estratificação por renda, utilizamos como referência a classificação do Cadastro Único, um sistema de informações do governo que identifica e caracteriza as famílias de baixa renda. Este instrumento considera que as famílias de baixa renda são aquelas que ganham até meio salário mínimo por pessoa; ou que ganham até 3 salários mínimos de renda mensal total. Em relação a este fator, selecionamos apenas duas variantes, baixa e média.

Vejamos a distribuição percentual no gráfico abaixo.

Gráfico 12 - Percentuais gerais de ocorrências considerando a renda familiar.

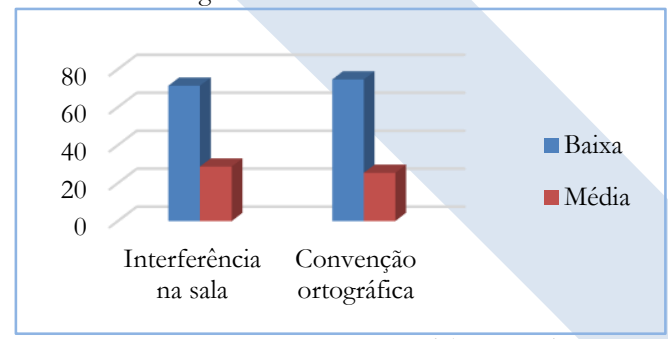

Fonte: Elaboração dos autores.

Observando o gráfico 12, vemos que a influência da fala é bastante alta em ambas as faixas, entretanto os alunos que mais cometeram erros ortográficos devido à influência da fala são aqueles cuja família possui uma renda familiar baixa. Esses erros correspondem a $71,3 \%$, enquanto os erros dos alunos cuja família possui uma renda familiar média representam $28,7 \%$. Em relação à convenção ortográfica, notamos índices semelhantes à variante anterior, $74,6 \%$ de erros de alunos cuja familiar é baixa, e $25,4 \%$ de erros de alunos 
cuja renda familiar é média. Com esse resultado, sinalizamos que a variável renda está fortemente relacionada aos problemas de escrita, pois mais renda significa mais acesso aos bens culturais, dentre a leitura, por meio de livros e suportes tecnológicos.

Os gráficos seguintes ilustram os percentuais dos fatores renda baixa e média, isoladamente.

Gráfico 13 - Percentuais de erros ortográficos considerando o fator renda familiar baixa.

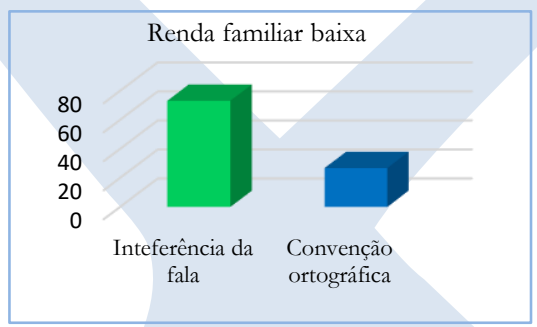

Fonte: Elaboração dos autores.
Gráfico 14 - Percentuais de erros ortográficos considerando o fator renda familiar média.

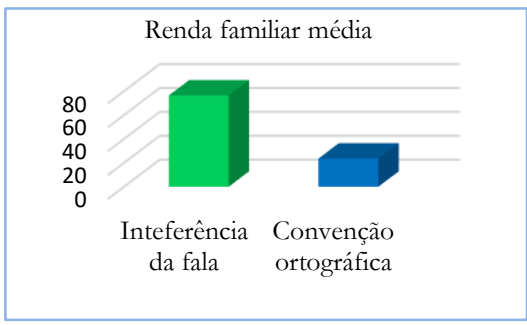

Fonte: Elaboração dos autores.

Vemos que a maior parte dos erros ortográficos tanto dos alunos de renda familiar baixa, quanto dos alunos de renda familiar média dá-se devido à influência da fala: baixa 73,2\%; média 76,4\%. Os percentuais dos outros erros ortográficos decorrentes da convenção ortográfica são menos expressivos: baixa 26,8\%; média 23,6\%, entretanto, os erros são mais expressivos numericamente para a renda baixa.

A análise dos dados levando em consideração o fator renda familiar e ano escolar está ilustrada nos gráficos 15 e 16.

Gráfico 15 - Percentuais de erros ortográficos considerando o fator renda familiar e ano escolar no $6^{\circ}$ ano do ensino fundamental.

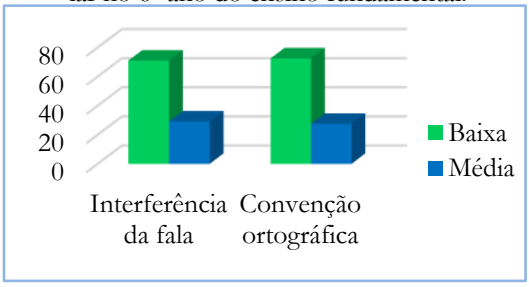

Fonte: Elaboração dos autores.
Gráfico 16 - Percentuais de erros ortográficos considerando o fator renda familiar e ano escolar no $9^{\circ}$ ano do ensino fundamental.

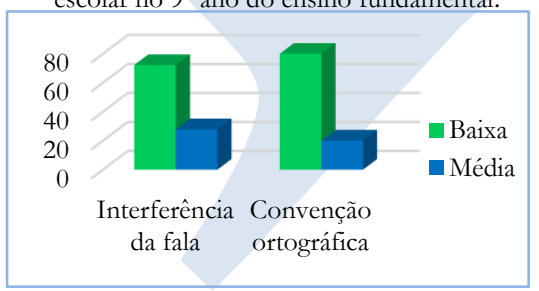

Fonte: Elaboração dos autores. 
Percebemos nos gráficos, 15 e 16, que são bastante expressivos os percentuais relacionados aos alunos cuja renda é baixa. O gráfico 15 , do $6^{\circ}$ ano, mostra que 70,9\% dos erros ortográficos influenciados pela fala são de alunos cuja renda é baixa, e 29,1\% são daqueles cuja renda é considerada média. Enquanto que 72,5\% dos erros por convenção ortográfica são de alunos cuja renda é baixa, e $27,5 \%$, de alunos cuja renda é média. A tendência se repete no gráfico 16 , do $9^{\circ}$ ano, os alunos cuja renda familiar é baixa, apresentaram $72,2 \%$ de ocorrências relacionadas aos erros ortográficos influenciados pela fala e $27,8 \%$ de ocorrências para aqueles cuja renda é média. Em relação aos outros erros de ortografia por problemas de convenção ortográfica, os alunos cuja renda é baixa apresentaram $80 \%$ de ocorrências e os alunos cuja renda é média apresentaram $20 \%$ de ocorrências. Ou seja, a despeito do avanço escolar, há leve diminuição da influência da fala, da diminuição de erros ortográficos para os alunos de renda baixa, sendo sempre maior do que os de renda média.

Considerando a variável escolaridade, optamos pelo grau de instrução da mãe, dividido em três variantes: ensino fundamental, médio e superior. A escolha pela variável referente ao sexo feminino se deu pelo fato de observarmos que houve um número expressivo de alunos participantes da pesquisa que residem em lares nos quais as mães são chefes de família, demonstrando que a presença da mãe na educação dos filhos é mais comum do que a presença dos pais. Vejamos os percentuais no gráfico a seguir:

Gráfico 17 - Percentuais gerais de ocorrências considerando a escolaridade da mãe.

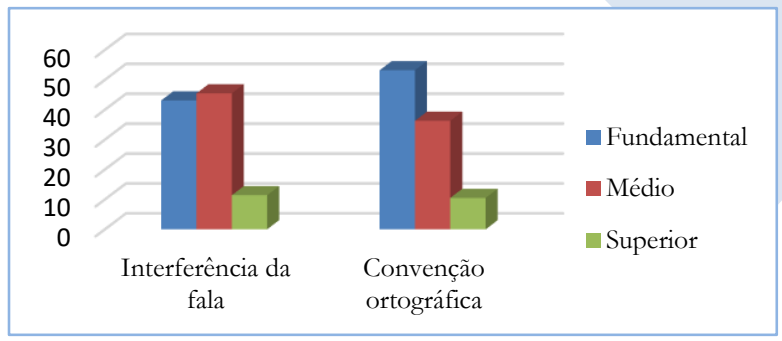

Fonte: Elaboração dos autores. 
Podemos perceber que os alunos cujas mães possuem o ensino médio apresentaram um maior percentual de erros por interferência da fala (45,5\%), seguido do percentual dos erros de alunos cujas mães possuem o ensino fundamental $(43,1 \%)$ e por fim, pelo percentual de erros cujas mães possuem o ensino superior (11,4\%). Enquanto, o percentual mais elevado no que concerne aos outros erros ortográficos decorrentes da convenção da escrita são de alunos cujas mães possuem o ensino fundamental (53,2\%); seguido do percentual de ocorrências dos alunos cujas mães possuem o ensino médio (36,3\%); e por fim, o percentual de ocorrências dos alunos cujas mães possuem o ensino superior (10,5\%). O que esses dados mostram é que quanto maior a escolaridade da mãe menor é a ocorrência de erros na escrita dos alunos, sendo mais atuante para a convenção ortográfica. Pode-se deduzir: que essas mães tem mais acesso à leitura e certamente podem proporcionar o mesmo aos seus filhos, inclusive com mais condições de acompanhamento do seu desempenho escolar.

Analisando os fatores ensino fundamental, médio e superior, isoladamente, verificamos os seguintes percentuais:

Gráfico 18 - Erros ortográficos considerando a escolaridade da mãe ensino fundamental.

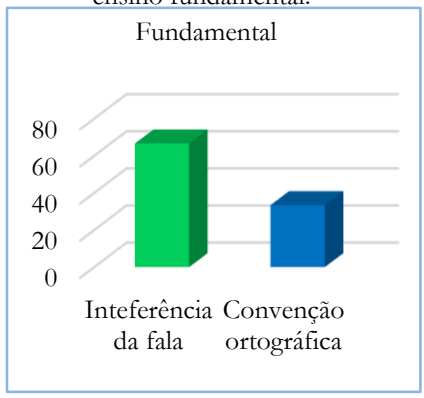

Fonte: Elaboração dos autores.
Gráfico 19 - Erros ortográficos considerando a escolaridade da mãe - ensino médio.

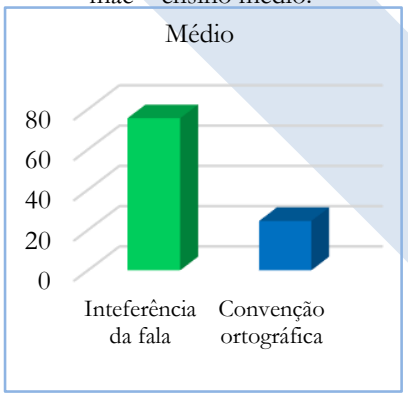

Fonte: Elaboração dos autores.
Gráfico 20 - Erros ortográficos considerando a escolaridade da mãe - ensino superior.

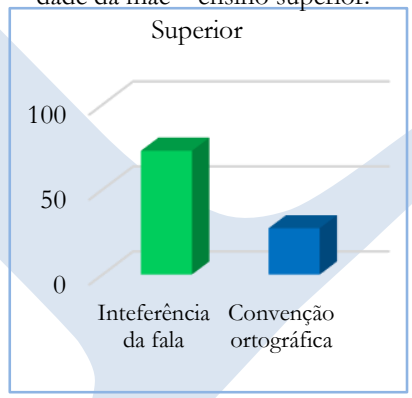

Fonte: Elaboração dos autores.

Esse gráfico confirma a tendência do anterior, erros decorrentes da influência da fala: ensino fundamental $66,6 \%$; ensino médio $75,5 \%$ e superior $72,8 \%$. Erros resultantes da falta de domínio da convenção ortográfica: ensino fundamental 33,4\%; ensino médio $24,5 \%$; e superior $27,2 \%$. 
O gráfico 21 faz essa análise separando escolaridade da mãe por ano de escolaridade do aluno:

Gráfico 21 - Percentuais de erros ortográficos considerando o fator escolaridade da mãe e ano escolar no $6^{\circ}$ ano do ensino fundamental.

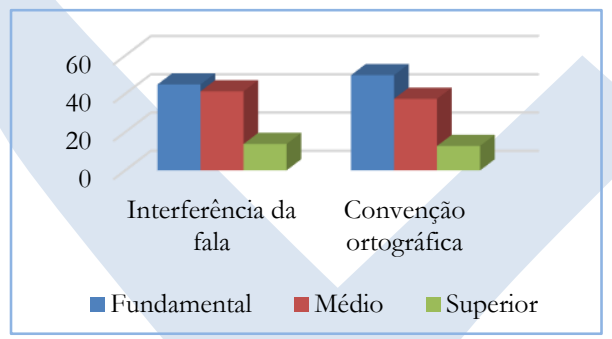

Fonte: Elaboração dos autores.
Gráfico 22 - Percentuais de erros ortográficos considerando o fator escolaridade da mãe e ano escolar no $9^{\circ}$ ano do ensino fundamental.

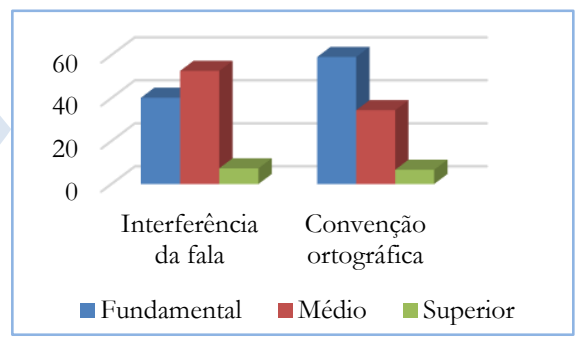

Fonte: Elaboração dos autores.

Notamos que, no $6^{\circ}$ ano, 44,9\% dos erros ortográficos referentes à interferência da fala nos textos escritos são de alunos cujas mães possuem o ensino fundamental; 41,3\% são de alunos cujas mães possuem o ensino médio e 13,8\% daqueles cujas mães possuem o ensino superior. Os outros erros ortográficos: 49,8\% são de alunos cujas mães possuem ensino fundamental, $37,4 \%$ são de alunos cujas mães possuem o ensino médio e 12,8\% daqueles cujas mães possuem o ensino superior. A tendência mostrada nos gráficos anteriores se mantém, à medida que a escolaridade do aluno avança, diminuem os erros e a influência das mães sobre esse processo aumenta, como vemos no gráfico 22. 40,1\% dos erros de ortografia concernentes à interferência da fala são de alunos cujas mães possuem o ensino fundamental; 56,6\% alunos cujas as mães possuem ensino médio e 7,3\% daqueles cujas mães possuem o ensino superior. Já os outros erros ortográficos: 59,1\% de alunos cujas mães possuem ensino fundamental; $34,3 \%$ de alunos cujas mães possuem o ensino médio e 6,6\% daqueles cujas mães possuem o ensino superior. No geral, os gráficos 21 e 22 mostram que o percentual de ocorrências tende a diminuir conforme aumenta o grau de instrução da mãe, porém acontece algo que contraria essa afirmação, quanto à variante ensino médio, no gráfico 22 , referente aos erros de por interferência da fala, para o que não temos justificativa plausível. 
O gráfico 23 apresenta a variável linguística gênero textual. Vejamos:

Gráfico 23 - Percentuais gerais de ocorrências considerando o gênero textual.

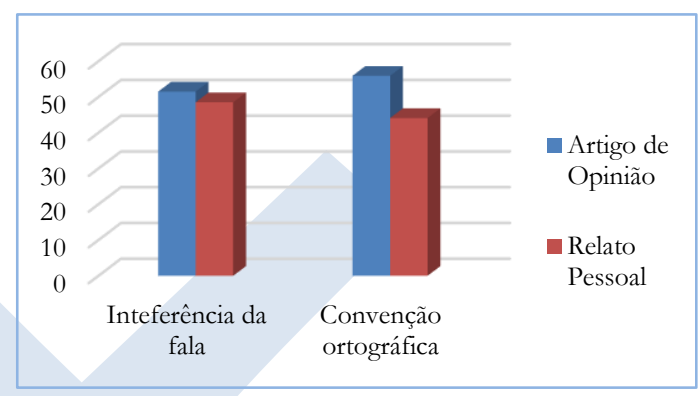

Fonte: Elaboração dos autores.

Os dados gerais apontam que o artigo de opinião foi o gênero textual que apresentou maiores índices de erros ortográficos tanto decorrentes da interferência da fala e em relação aos decorrentes da falta de familiaridade dos alunos com a convenção ortográfica. Assim, de 1091 ocorrências por interferência da fala: no artigo de opinião ocorreram 51\%; no relato pessoal ocorreram 48,5\%. No que diz respeito aos outros erros por problemas de convenção ortográfica, de 447 ocorrências, no artigo de opinião ocorreram 55,9\% e no relato pessoal ocorreram 44,1\%. Esses resultados nos surpreendem, pois esperávamos que se desse o contrário: o relato pessoal se aproxima mais da vivência do aluno e nos pareceu que isso pudesse gerar um menor monitoramento do texto.

Analisados de forma isolada, os índices nos gráficos a seguir confirmam essa tendência. 
Gráfico 24 - Percentuais de erros ortográficos considerando o fator artigo de opinião.

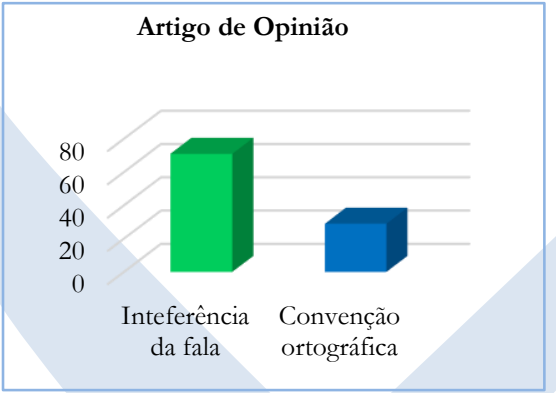

Fonte: Elaboração dos autores.
Gráfico 25 - Percentuais de erros ortográficos considerando o fator relato pessoal.

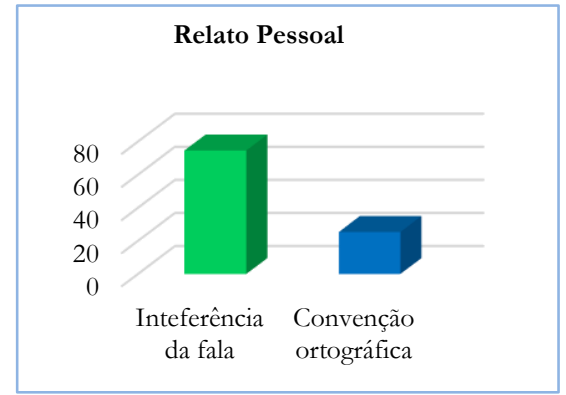

Fonte: Elaboração dos autores.

No artigo de opinião, os erros por interferência da fala são de $71 \%$ contra $29 \%$ de outros erros decorrentes da falta de domínio da convenção ortográfica. No relato pessoal, o percentual de erros referentes à influência da oralidade também foi alto, $74,6 \%$ contra 25,4\% relacionado aos outros tipos de erros da escrita. Agora vejamos como se distribuem em relação ao ano de escolaridade:

Gráfico 26 - Erros ortográficos considerando o fator gênero textual e ano escolar no $6^{\circ}$ ano do ensino fundamental.

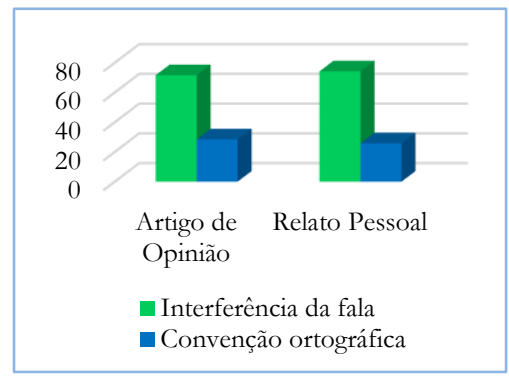

Fonte: Elaboração dos autores.
Gráfico 27 - Erros ortográficos considerando o fator gênero textual e ano escolar no $9^{\circ}$ ano do ensino fundamental.

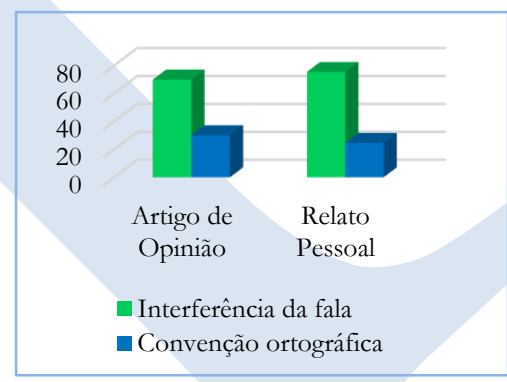

Fonte: Elaboração dos autores.

Podemos observar que os erros ortográficos por interferência da fala apresentaram maiores percentuais de ocorrências nos dois gêneros textuais (artigo de opinião e relato pessoal), tanto no $6^{\circ}$ ano, quanto no $9^{\circ}$ ano, e os outros erros ortográficos apresentaram percentuais menores: No artigo de opinião (gráfico 26), 71,6\% dos erros estão relacionados à interferência da fala e 28,4\% representa os erros por problemas de convenção ortográfica, 
enquanto no relato pessoal, $74,2 \%$ dos erros de escrita são referentes à interferência da fala e $25,8 \%$ referente aos outros erros ortográficos por problemas de convenção. No gráfico 17, a distribuição percentual dos erros do $9^{\circ}$ ano, percebemos que no artigo de opinião, $69,9 \%$ dos erros estão relacionados à interferência da fala e 30,1\% representa outros erros ortográficos por problemas de convenção, enquanto no relato pessoal, 75,4\% dos erros são referentes à interferência da fala e 24,6\% referente aos outros erros ortográficos. Em suma, não há grande diferença entre a escolaridade e as ocorrências de erros.

Com relação variável linguística classe gramatical, conforme as variantes substantivos, adjetivos, conjunção, pronome e verbo deu-se a seguinte distribuição.

\section{Gráfico 28 - Percentuais de ocorrências considerando o gênero textual.}

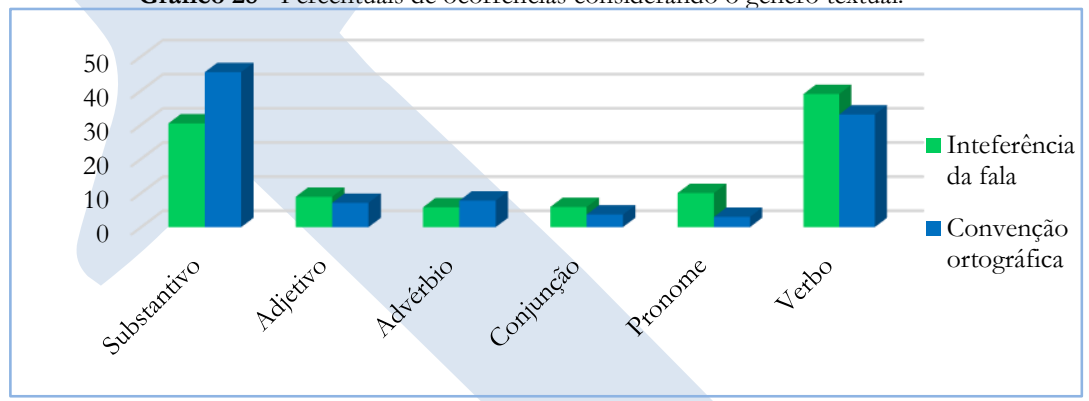

Fonte: Elaboração dos autores.

O maior percentual de ocorrências por interferência da fala se deu da seguinte forma: verbo $(39 \%)$, substantivo $(30,4 \%)$, pronome $(10 \%)$, adjetivo $(8,9 \%)$, conjunção (5,9\%) e advérbio (5,8\%). Em relação aos outros erros, o maior percentual de ocorrências se deu da seguinte forma: $(45,4 \%)$, verbo (33\%), advérbio $(7,8 \%)$, adjetivo $(7,1 \%)$, conjunção $(3,7 \%)$ e pronome (3\%). Notamos que, tanto os erros ortográficos por interferência da fala, quanto os erros por problemas de escrita nas duas séries observadas, a maior ocorrência se deu nos verbos e nos substantivos. Na primeira variante destacamos a maior ocorrência nos verbos e na segunda variante destacamos a maior ocorrência nos substantivos. Como demonstrado a seguir, essa tendência se confirma em relação aos anos escolares: 
Gráfico 29 - Percentuais de erros ortográficos considerando o fator classes gramaticais e ano escolar no $6^{\circ}$ ano do ensino fundamental.

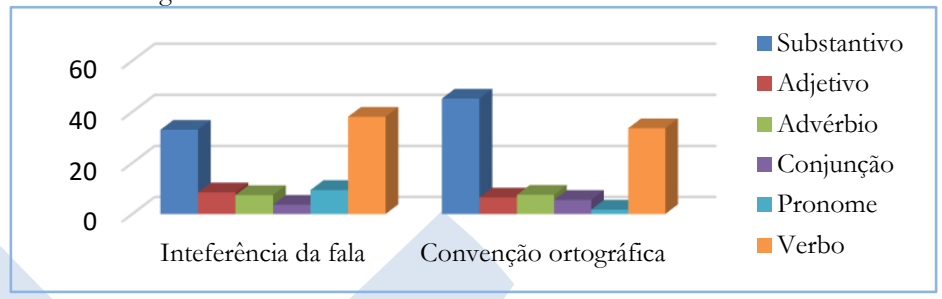

Fonte: Elaboração dos autores.

Gráfico 30 - Percentuais de erros ortográficos considerando o fator classes gramaticais e ano escolar no $9^{\circ}$ ano do ensino fundamental.

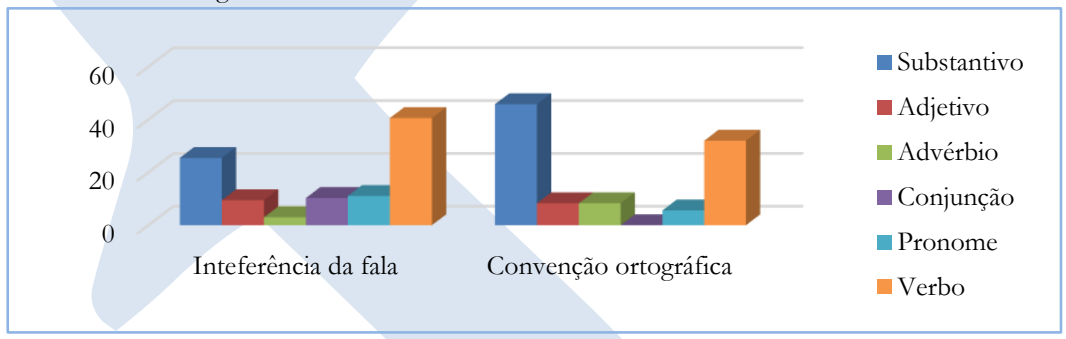

Fonte: Elaboração dos autores.

Em relação os erros ortográficos por interferência da fala na escrita dos alunos do $6^{\circ}$ ano, houve os seguintes percentuais: $33 \%$ nos substantivos; $8,5 \%$ nos adjetivos; $7,4 \%$ nos advérbios; 3,6\% nas conjunções; 9,4\% nos pronomes e 38,1\% nos verbos. Já em relação aos outros erros ortográficos por problemas de convenção, os percentuais foram: $45 \%$ nos substantivos; $6,5 \%$ nos adjetivos; 7,5\% nos advérbios; $5,5 \%$ nas conjunções; $1,7 \%$ nos pronomes e 33,6\% nos verbos. No gráfico 14, que representa a distribuição de ocorrências de erros ortográficos nas produções dos alunos do $9^{\circ}$ ano, em relação aos erros influenciados pela fala, percebemos os seguintes índices: 26\% nos substantivos; 9,5\% nos adjetivos; 3\% nos advérbios; $10,3 \%$ nas conjunções; $11,1 \%$ nos pronomes e 40,6\% nos verbos. Já em relação aos erros inerentes aos problemas de convenção ortográfica foram: $46 \%$ nos substantivos; $8,3 \%$ nos adjetivos; $8,3 \%$ também nos advérbios; $5,6 \%$ nos pronomes e $32 \%$ nos verbos. Ressaltamos que não houve nenhuma ocorrência de erros por problema de convenção ortográfica em relação à variante conjunção. De fato, esses índices refletem mais a 
quantidade de usos dessas classes nos textos em geral, das quais o substantivo, seguido de verbos, é sempre o mais frequente.

\section{Considerações finais}

O objetivo geral deste artigo foi apresentar a descrição de erros ortográficos na escrita de alunos dos $6^{\circ}$ e $9^{\circ}$ ano do ensino fundamental, fazendo uma comparação das ocorrências de erros ortográficos nessas duas séries, com a finalidade de propor atividades didático-pedagógicas que visem à melhoria da escrita desses alunos.

Por meio dessa investigação, percebemos que a língua falada possui uma influência significativa na escrita dos alunos das séries finais do ensino fundamental, revelando um desconhecimento dos usos linguísticos de cada modalidade, principalmente por parte dos alunos do $6^{\circ}$ ano. Com isso, constatamos que os discentes, ao chegarem a esse ciclo de escolaridade, apresentam nas suas produções escritas muitos problemas de ortografia, demonstrando a necessidade de intervenção pedagógica que ajude a superação desses problemas de escrita, bastante comuns. Também vimos que os fatores sociais são de uma importância para o aprendizado da escrita na sua forma padrão, ortográfica.

Mediante a comparação dos resultados da pesquisa realizada no $6^{\circ}$ e $9^{\circ}$ anos, constatamos que a ocorrência desses problemas de escrita diminui ao longo dos anos. Isso comprova que os alunos do último ano do ensino fundamental possuem maior conhecimento da língua escrita, pois o número de ocorrências de erros ortográficos é menor, porém é um quantitativo preocupante, demonstrando a necessidade de uma intervenção mais efetiva.

Este trabalho nos dá elementos concretos para refletir sobre quais estratégias didático-pedagógicas podem ser desenvolvidas, com o objetivo de minimizar a ocorrência dos erros ortográficos nas produções textuais dos alunos. Este estudo permitirá desenvolver uma proposta interventiva por meio das tecnologias digitais de comunicação e informação (jogos digitais e atividades on-line), incluindo atividades específicas para cada tipo de fenômeno investigado. 
Esperamos também que os dados aqui fornecidos sirvam de parâmetros para outros trabalhos de pesquisa, de modo que possamos fazer generalizações sobre a língua escrita do português brasileiro.

\title{
AN ANALYSIS OF WRITING IN THE TEXTS OF STUDENTS OF FUNDAMENTAL EDUCATION
}

\begin{abstract}
This work presents a research on the spelling errors resulting from the influence of speech in writing and those resulting from the student's lack of familiarity with orthographic conventions, in the written textual productions of students from the 6th and 9th years of elementary school II, from a public school, in the municipality of Parauapebas (PA). For this, the theoretical approach is based on the approaches of Morais (2003), Nóbrega (2013), Bortoni-Ricardo (2005); Mollica (2016); among others. As it is a qualitative and quantitative research, linguistic data were collected from a text production activity (opinion article and personal report), resulting in a corpus with 1,638 data. The results obtained after data treatment using the Goldvarb X program, allowed us to conclude that students reach the 6th year of elementary school with more spelling problems related to speech interference in writing $(72.7 \%)$, than those resulting from orthographic convention problems $(27.3 \%)$. In addition, we conclude that these orthographic problems are correlated both to extralinguistic factors (gender, income, mother's education, school year), and to linguistic factors (textual gender, grammatical class).
\end{abstract}

KEYWORDS: Orthographic convention; Spelling errors; Speech interference in writing.

\section{REFERÊNCIAS}

BRASIL. Base Nacional Comum Curricular (BNCC). Brasília: MEC, 2017.

BORTONI-RICARDO, Stela Maris. Nós cheguemos na escola, e agora? Sociolinguística e Educação. São Paulo: Parábola Editorial, 2005.

Editorial, 2004.

Educação em língua materna: a sociolinguística na sala de aula. São Paulo: Parábola

CAGLIARI, Luiz Carlos. Alfabetização e escrita. São Paulo: Scipione, 2002.

FÁVERO, Leonor Lopes; ANDRADE, Maria Lúcia C. V. O.; AQUINO, Zilda Gaspar Oliveira. Oralidade e escrita: perspectiva para o ensino de lingua materna. 3. ed. São Paulo: Cortez, 2002.

FERREIRO, Emilia; TEBEROSKY, Ana. Psicogênese da língua escrita. Porto Alegre: Artes Médicas, 1999.

LORANDI, Aline. Aquisição da variação: a interface entre aquisição da linguagem e variação linguística. Alfa: Revista de Linguística, São Paulo: UNESP, v. 57, 133-162, 2013. 
MOLLICA, Maria Cecilia. Influência da fala na alfabetização. 2. ed. Rio de Janeiro: Tempo Brasileiro, 2016.

MORAIS, Artur Gomes de. Ortografia: ensinar e aprender. São Paulo: Editora Ática, 2003.

NÓBREGA, Maria José. Ortografia. São Paulo: Melhoramentos, 2013.

PAIVA, Maria da Conceição de. A variável gênero/sexo. In: MOLLICA, Maria Cecilia; BRAGA, Maria Luiza. Introdução a sociolinguística: o tratamento da variação. 4. ed. São Paulo: Contexto, 2010.

TRAVAGLIA, Luiz Carlos. Gramática e interação: uma proposta para o ensino de gramática. 14. ed. São Paulo: Cortez, 2009.

Recebido em: 30/042020. Aprovado em: 20/05/2020. 